\title{
Developing Maintenance Management Supportive Framework as Measures for Effective Maintenance Management Practices in Selected Nigerian Universities
}

\author{
Chinda Ebele Roseline and Wokekoro Ebiwari
}

\section{ABSTRACT}

Overtime buildings and its components would become obsolete. If the rate of building deterioration is not checked and managed, these buildings and its components will get to their ultimate functional life quicker while we contend with increasing user population. Maintenance management is an essential aspect of any university that must be given adequate attention if the university must achieve its academic goals. Policy guidance for maintenance activities and management control over maintenance program are the key provision of Maintenance management. This study develops a maintenance management supportive framework in selected Universities: Rivers State University, Imo State University and University of Uyo in Nigeria and how it serves as effective measures for maintenance management practices. The data used for the study was gotten from interview conducted on the directors of works and maintenance managers of the three selected university using structured interview method. 3 Directors of Works and 45maintenance managers in accordance with the $\mathbf{1 5}$ maintenance units found in each of the universities was used for the study. These university officials are responsible for the management and maintenance of tertiary institution's buildings.For this study, the Content and thematic approaches were used in analyzing the data gathered from all interviews. The study revealed that there were intentionally designed existing plans and procedures for carrying out maintenance works, but found to be ineffective and inefficient, affecting the current condition of the tertiary institutions' buildings. The study developed a maintenance management supportive framework to assist maintenance managers surmount complex maintenance task. Therefore, adopting this framework will give government directions on adequate funding based on needs, plan maintenance management strategy and building condition assessment to improve maintenance management practices in Nigerian Universities.

Keywords: Developing, Maintenance, Management, Supportive Framework, Nigerian Universities.

\section{INTRODUCTION}

It is imperative for tertiary institutions to embark on maintenance activities on a regular basis to make sure that their facilities are operating safely and effectively. This cannot be over emphasized for a university whose primary concern is to provide a safe environment for, learning, teaching, research among staff, students, and visitors (Lateef, et.al.,2010). Therefore, it is of great importance that the maintenance department of a university creates means of ensuring facilities are functioning properly, because any unexpected disruption could seriously affect the safety of students and staff (Khalil and Husin,2011). It is therefore of great necessity that facilities are risk appraised to check for factors that may contribute potentially to equipment failure and such factors have to be spotted out, mitigated, or eliminated to ensure safety. Maintenance necessitates the expenditure of both resources and time which must be
Submitted : December 02, 2021

Published : January 28, 2022

ISSN: 2507-1076

DOI: $10.24018 /$ ejbmr.2022.7.1.1190

\section{Ebele Roseline*}

Department of Estate Management, Rivers State University, Port Harcourt, Nigeria.

(e-mail: cashbrain7642@ gmail.com) W. Ebiwari

Department of Estate Management, Rivers State University, Port Harcourt, Nigeria. (e-mail: ebi_wokekoro ${ }^{\circledR}$ yahoo.com)

*Corresponding Author managed carefully to reduce overhead cost in maintenance operations.

Maintenance management framework could be seen as the policy for managing building maintenance. It applies to all maintenance departments or units that have maintenance responsibilities within their portfolio. Maintenance management framework is made up of policy, guidelines and policy advice notes used by maintenance or facilities managers. A Maintenance management framework is made of interlinked items which support a definite approach to a specific aim (Hesham, 2015).

In Nigerian universities, studies carried out revealed that there are existing plans and procedures of carrying out maintenance works, which are intentionally designed to improve the condition of tertiary institution buildings. But these plans and procedures are found to be ineffective and inefficient, affecting the current condition of the tertiary institutions' buildings. It is therefore imperative that adequate maintenance works be included in the general plan of action 
of the organization as to manage its interaction with other functions (Lee,2003). Once this is attained, maintenance at this point will be given the attention it deserves and be taken as one more important responsibility of the organization, which contributes to the achievement of the organization specific goals. Overtime as maintenance advanced, various authors have proposed what they believe as the optimum techniques, steps, sequences of activities, or models to fulfill this responsibility throughout the history of maintenance. Because of the aforementioned concerns, the maintenance management framework proposed in this study will now encompass both developed and in-use assets for effective decision-making in asset maintenance and life cycle management. Based on this, methods and models that can order and aid decision-making processes in maintenance management can be discovered.

\section{LITERATURE REVIEW}

\section{A. Effective Maintenance Management}

In order to attain efficient maintenance management, maintenance processes must be continuously improved. Asset maintenance planning, maintenance operations scheduling, maintenance actions execution, asset suitability assessment (redesign of equipment if necessary), and operations effectiveness review are six areas where continuous improvement is critical, according to Hassanain, Froese, and Vainer (2001). Maintenance activities are primarily concerned with keeping equipment in good working order, but they can also include procurement and inventory management. Direct management involvement in maintenance operations, technical and interpersonal training, inventory and procurement control, the availability of a computerized maintenance management system, and a standardized work order system were all considered essential for maintenance operations (Hesham, 2015).

Furthermore, (Marquez and Gupta, 2006) argued that for a maintenance management system to be operated effectively, three maintenance related functions, namely planning, organization, supervision, and control, must be properly coordinated.

\section{FUNCTIONS OF EFFECTIVE MAINTENANCE MANAGEMENT}

Maintenance management is responsible for a variety of tasks that help an organization's operations run smoothly. In most circumstances, there are three levels of business activity: strategic, tactical, and operational (Marquez and Gupta, 2006). The strategic activities are aimed at creating company priorities and linking them to maintenance needs. At the tactical level, the focus is on determining the best maintenance skills, tools, and equipment for the job. At the operational level, efforts are focused on ensuring that maintenance goals are completed within the time frame set by adequately experienced personnel using appropriate instruments.

\section{Maintenance Management Framework}

A maintenance management framework is a conceptual structure that allows numerous tasks to be structured, coordinated, monitored, and managed in a systematic manner so that maintenance work can be completed successfully (Hesham,2015). Because implementing a maintenance management framework is a tough task that requires the involvement and help of senior management as well as all critical functions, researchers developed a number of maintenance management frameworks in the 1990s (Hesham and Lai, 2015). Hesham, Chris, and Lai (2013) developed a maintenance management framework with three major components: management system design, maintenance management decision-making, and a toolbox for statistically modelling system failures.

They stressed the importance of training in order to improve maintenance personnel's expertise and allow them to work in a safe environment. A maintenance framework, according to Hesham, Chris, and Lai (2014), should include two management processes: process effectiveness analysis and process efficiency analysis. The former seeks to identify any major issues as well as potential solutions, whilst the latter focuses on determining appropriate techniques. They proposed an eight-stage evaluation loop for maintenance management processes, including determining current performance, analyzing quality issues, analyzing downtime issues, analyzing potential solutions, analyzing maintenance procedures, planning, and executing actions, data collection, including event observation, and data processing.

Lee(2003) presented a maintenance framework in the shape of a pyramid structure. It is made up of 11 blocks that are organized into five tiers and is backed up by a preventive maintenance program at the base. A Computerized Maintenance Management System (CMMS), as well as a work order system, spare parts supply, and maintenance personnel training, are all included in the second level. The third level includes predictive maintenance, operational participation, and Reliability Centered Maintenance (RCM). The fourth level focuses on establishing overall productive maintenance and improving financial performance through statistical methodologies. The highest level of the framework is concerned with continuous process improvement.

A four-level design for maintenance management has been presented by Lee (2003). The creation of asset maintenance strategies, as well as the human resource management that goes with it. The first is to maintain track of and regulate individual assets throughout their lives in order to ensure that they perform as expected. The next stage is to develop a measurement system that would enable performance measurements to be collected. The maintenance activity planning and scheduling portion is the third section.

The fourth strategy focuses on one or more of the eight tactics listed above: run to failure, redundancy, scheduled replacement, scheduled overhaul, ad-hoc maintenance, preventative maintenance (either age-based or use-based), condition-based maintenance, and, if necessary, redesign. In order to accomplish continuous improvement, the third level requires implementing two incredibly successful maintenance methodologies, TPM and RCM. The highest 
level of maintenance re-engineering strives to retain the improvements obtained.

Tsang (2002) defines a maintenance system as a transformation. assessing current asset performance, planning maintenance, and maintaining control over maintenance operations Identifying goals, procuring resources, prioritizing high-impact equipment, identifying the most critical components, adopting a maintenance policy, and deciding on an acceptable maintenance approach are all steps in Waeyenbergh and Pintelons (2002) six-step structure (either block-based or time based).

Following a review of publicly accessible maintenance frameworks Takata, Kimura, Van Houten, Westkamper, Shopitalni, Ceglarek, and Lee (2004) reinterpreted the role of maintenance in the development life cycle. According to them, a framework should provide a link between the product development and operation phases, which should be connected through maintenance strategy planning. The first loop employs Deming's PDCA (Schedule-Do-ControlAction) cycle to schedule maintenance activities, select a task (such as inspection, monitoring, diagnosis, or treatment), and complete the activity.

Márquez, Moreu de León, Gómez Fernandez, Parra Márquez, and López Campos provided a conceptualframework for maintenance management (2009). It is made up of eight blocks that are logically ordered to cover four main functions: effectiveness, efficiency, assessment, and improvement. The definition of maintenance targets and related Key Performance Indicators (KPIs), asset prioritization, the specification of a suitable maintenance strategy, and the remediation of high-impact weak points are all covered by effectiveness. Efficiency encompasses the planning and optimization of preventive maintenance plans, including resources and schedules. This assessment covers maintenance execution, monitoring, and control, as well as asset life cycle analysis and replacement optimization. Improvement addresses concerns about ongoing improvement by employing new technologies.

Naughton and Tiernan (2012) outlined a nine-step process for developing and implementing an individual maintenance strategy. The nine sequential steps are to focus on the positives and define one's position, as well as to identify constraints and limitations (complexity assessment), system classification, machine classification, policy selection, align performance indicators, structure maintenance data, implement and monitor, and feedback. All of the frameworks discussed in this section, to the author's knowledge, are conceptual in nature, with no information on their implementation or validation.

According to previous research, an expert's assessment of risks and potential function failures, as well as their mapping to an organization's "risk enthusiasm" and business strategy, is typically used to choose a maintenance plan or policy. Maintenance performance is important since maintenance procedures are typically labour intensive. To the best of the researcher's knowledge, a number of maintenance management frameworks have been developed (Hassanainet al., 2001; Waeyenbergh andPintelon, 2002); Takata et al. (2004), but none have been validated in a practical scenario.

The framework concept, on the other hand, appears to provide a strong foundation for the building of a maintenance management framework for the healthcare sector, according to Márquez et al. (2009), as it appears to be the most closely connected with the study's objectives. The framework model is cyclical and dynamic, allowing interactive participation of stakeholders, thanks to a computerized management system. In addition, the framework allows for process optimization through the use of certain tools and data/information obtained from various maintenance chores.

\section{RESEARCH METHODS}

Survey Research design was used for this study and was conducted in 3 selected universities (Rivers State University, Imo State University and University of Uyo) in Nigeria. In order to achieve the aim, this study utilized semi-structured interview on high ranking officials: 3 Directors of Works and 45 maintenance managers (Heads of Maintenance Unit). These officials of the university are responsible for the management and maintenance of the university buildings. Thematic Content Analysis was used for the analysis of data from the interviews conducted. Burnard (1991) examined in details Thematic Content Analysis and stated it as a process that is aimed at producing an elaborate and systematic recording of the themes and issues discussed in the interviews and connecting both the themes and interviews together under a reasonably comprehensive category system. Another name for themes is codes, they are gotten by the researcher from existing theoretical ideas (deductive coding) or from the raw data itself (inductive coding) Marks and Yardley (2004). The Inductive and deductive coding system was adopted for this study.On the other hand, the content analysis approach results are a numerical description of characteristic of a given text or series of images, whereas, according to Marks and Yardley, (2004) the thematic analysis focus on the qualitative aspects of the material analyzed. Content system is seen as a partial quantitative method (Julien 2008), and gives way for systematic qualitative analysis. For this study, the Content and Thematic approaches were used in analyzing the data gathered from all interviews. Burnard (1991) called the system 'Thematic Content Analysis'

\section{RESULTS AND DISCUSSION OF FINDINGSEXISTING Maintenance Management Plan}

In order to ascertain the existing maintenance management plan used in the various institutions; key informants' information was derived from the Directors of Works and Head of Maintenance units which they admitted that the existing maintenance management practices adopted includes planned and unplanned maintenance.

The Director of Works in Imo State University stated that:

"Planned maintenance is necessitated by the routine and periodic maintenance carried out in the form of preventive and corrective maintenance. And the adoption of unplanned maintenance is based on emergency repairs that require immediate attention. And this could be the determinant and identified factor including funding contributing to the rising maintenance problems resulting to poor maintenance management practices". 
The Director of Works in Rivers State University also indicated that:

"The existing maintenance plan is based on availability of funds allocated to maintenance.And maintenance works are carried out as the needs of the maintenance arises.Even if there is lots of maintenance works required of the institution, priorities are placed on the immediate needs; in form of pay as you go pattern".

On procedure adopted for effective maintenance management practices; one of key information from a maintenance manager of Units in maintenance department at university of Uyo indicated that:

"The procedure of carrying out effective maintenance management practices in their institution is intentionally designed to improve condition of university's infrastructure, but are found to be ineffective, affecting the current condition of the university buildings".

The key informants' information from the study revealed that there was an existing maintenance management plan in the universities studied. The existing maintenance management plan that the institutions taught that was workable; was receiving official complaints from building end-users (written or oral reports) to maintenance department, as well as observation made by the maintenance officers during building surveys.This followed by action taken in the area of inspections, assessment and estimation of works, then approval of funds by the Vice Chancellors.Tendering for works is carried out to select contractors, select methods of executing maintenance activities as well as supply of building materials. key informants revealed that proper maintenance execution is considered through in-sourcing, outsourcing and direct labour.All these processes of the existing maintenance management practices have brought fairly improve condition of the institution's buildings.

An in-depth interview revealed that the existing maintenance management plan is based on availability of funds allocation to maintenance works. And also, repairs are done when the need arises, even though there are lots of request for maintenance works.And priorities are placed on the immediate needs of the institutions. The study further indicated that procedures of carrying out maintenance works in institutions are intentionally designed to improve the condition of tertiary institution buildings.But the procedures are found to be ineffective and inefficient, affecting the current condition of the tertiary institutions' buildings.And there is need for a maintenance management supportive framework to be developed, as a measure to improve the current condition of buildings that are in a fair state of repairs.

\section{DEVEloped MaInTENANCE MANAGEMENT SUPPORTIVE FRAMEWORK}

The developed maintenance management supportive framework takes clue from Mojela (2012) and Ikediashi (2014). It will help maintenance managers at Nigerian tertiary institutions with the difficult task of maintenance. Fig.1depicts the maintenance management supportive framework, which consists of six primary processes that are divided into three major stages to aid maintenance managers in making decisions on maintenance management practices. There are three stages to identifying stakeholders for the set standards: conceptual, action, and implementation. The processes are interconnected with each other using link arrows to further describe the framework.

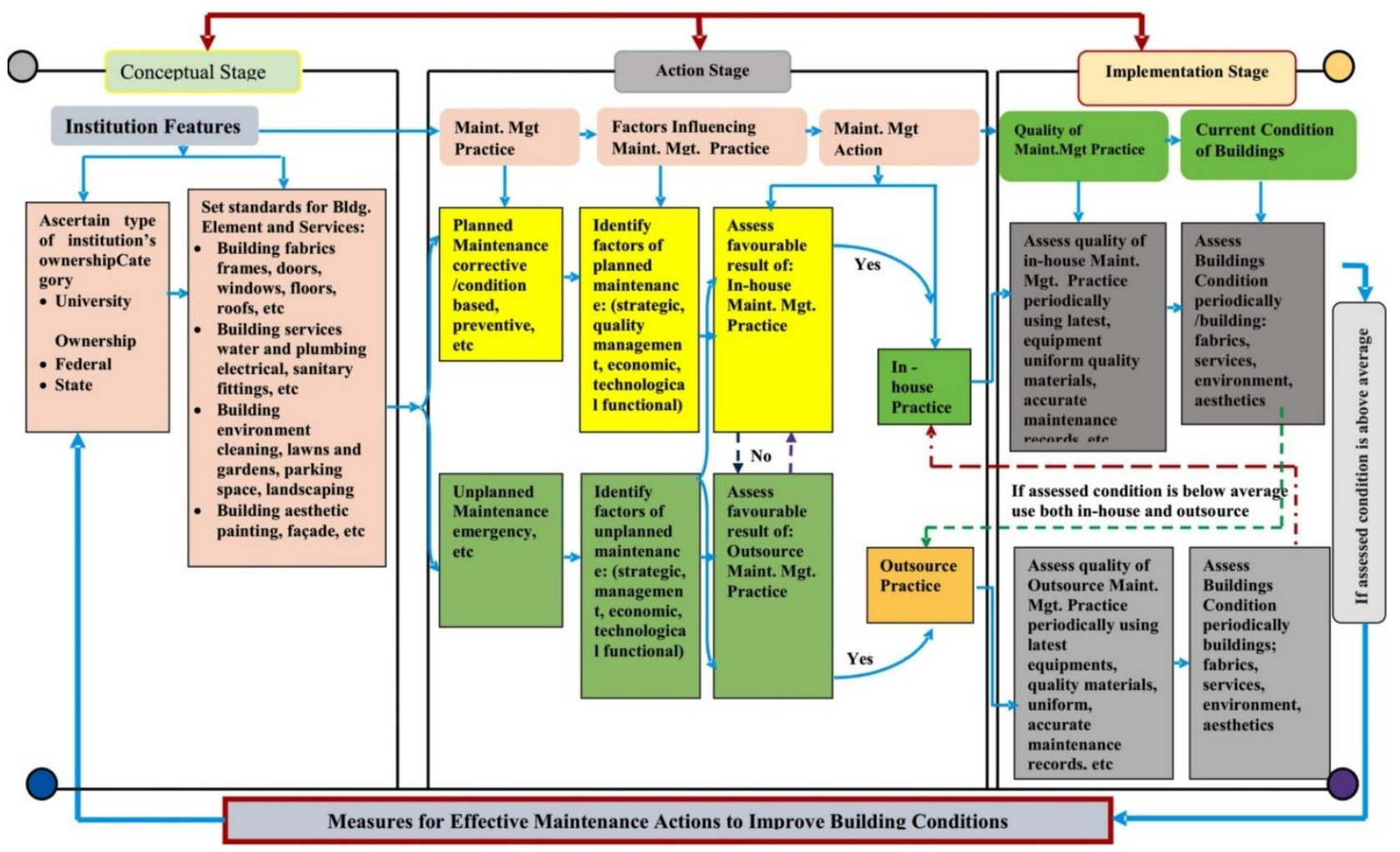

Fig. 1. Proposed maintenance management support framework. Source: Autor's Field Survey, 2021. 
The assessment feedbacks are expected to be fed into the gaps of quality maintenance practices and the condition assessment results found with the building fabrics, building services, building environment, and building aesthetic in a chain process with the goal of achieving optimal results, as indicated by the linking arrows. The many elements or portions of the framework produced by this study make it simple for maintenance management practices and maintenance managers to properly manage and maintain tertiary institution buildings.

\section{SUMMARY OF OPINIONS OF KEY INFORMANTS ON THE Proposed DEVELOPED MAINTENANCE MANAGEMENT SUPPORTIVE FRAMEWORK}

The elicited information is sent forward into the feedback loop primarily with issues involving maintenance management with the inhabitants in mind, according to key informants, and it comprises the following:

The suggested maintenance management support system is divided into six (6) core processes and three (3) stages. The flow sequences between the processes are depicted in the framework. In order to promote successful maintenance activity to enhance building conditions, the framework established a pattern of transaction from one stage to the next. The main objectives of the maintenance management supportive framework, according to the findings, are to:

- Establish standards for building elements and services by identifying institution characteristics (such as ownership type and category).

- Ensure the type of maintenance management to be practiced.

- Ensure factors influencing maintenance management practice are overcome.

- Ensure maintenance management action taken produces favourable results.

- Provide points for taking proper maintenance supportive action.

- Ensure the quality of maintenance management practice is assessed.

-Ensure adequate funds are allocated to maintenance work.

-Ensure the quality of building conditions is assessed.

The main goal of the framework's conceptual stage is to determine the kind and category of ownership of the institution in order to establish criteria and a plan for the correct maintenance of building elements and services. This stage explains how to define maintenance management activities based on the scope of the project and the institution's (federal/state) features in order to make money accessible for maintenance projects. Maintenance managers are also expected to develop standards and make plans to improve building conditions at this stage (fabrics, services, environment and aesthetics). The maintenance management programs should be prioritized or grouped according to the scope established by managers, taking into account cash provided by the institution's owner.

This stage of action would entail preparing for the maintenance management to be carried out in light of the building's condition: planned and unplanned maintenance. This key goal includes taking action on the issues that influence maintenance management procedures. This diagram depicts the function of maintenance managers during the Action Stage. The process is assessed in light of the techniques for carrying out maintenance work, which include in-sourcing and/or outsourcing. Maintenance managers are expected to evaluate the potential risk connected with elements impacting outsourcing or in-sourcing methods in terms of strategic, managerial, quality, economic, technological, and function aspects for each securing option selected.

As a result, it is expected that if the sourcing option for maintenance management is significant with the variables considered, that sourcing option should be chosen. The maintenance managers' work is centered on re-evaluation of results, directing how to meet set criteria, and adhering to policies, regulations, and plans established during the action stage.

Maintenance managers' role in the implementation stage, according to the study: Maintenance executions are carried out at this stage with the goal of monitoring and controlling the quality of maintenance work as a means of carrying out planned maintenance activities. By adopting and implementing all maintenance plans, adhering to guidelines, standards, and employing toolkits, maintenance managers are expected to periodically assess the quality of maintenance work, use of up-to-date equipment, good, uniform, quality building materials, accurate maintenance records, and so on. In addition, maintenance managers are expected to check the condition of buildings on a regular basis, including the textiles, services, environment, and aesthetics, in order to perform above average. The funding allocated for maintenance work at this stage will be determined by the buildings' condition evaluations.

The framework's functions, according to the findings, are to:

- Ensure that processes are connected to one another through link arrows.

- Make sure that input is incorporated into holes in quality maintenance methods.

- Ensure that the building condition assessment yields positive results.

- Ensure that both outsourcing, and in-sourcing maintenance management techniques are used to obtain the best outcomes.

- Ensure that building maintenance management practices, as well as maintenance managers, are clearly understood.

- Ensure that tertiary institution buildings are wellmanaged and maintained.

The framework's maintenance principles, according to the report, will include:

- Periodically examine the quality of maintenance management techniques (both in-house and outsourced).

- Periodically assess the state of the building.

- Evaluate the benefits of in-house and outsourced) procedures.

- Based on in-source and outsource strategies, use up-todate equipment, good uniforms, quality materials, accurate maintenance records, and so on.

- Allocated maintenance funds feedbacks be fed into building conditions report. 
- Before each budget year, building condition evaluations must be updated, examined, and analyzed.

This maintenance approach would serve as a strong foundation for allocating finances and other resources for maintenance. The principles will also serve as a foundation for developing a maintenance strategy for how maintenance will be carried out in order to overcome the obstacles that influence maintenance management practice selection.

The principles must also ensure that maintenance is prioritized based on urgency, impact on achievement, and adherence to any specific set of criteria. The framework's maintenance principle will direct federal and state governments as owners of the institutions, resulting in highlevel achievement of funding guidelines and toolkits as established. Implementing the framework developed in this study will help maintenance managers better understand maintenance management procedures and manage and maintain building conditions in tertiary institutions.

\section{CONCLUSION AND RECOMMENDATIONS}

This research presented a maintenance management supportive framework as one of the most effective ways to enhance building conditions in Nigerian universities. A maintenance management supportive framework is an important instrument for the execution of maintenance works in Nigerian universities, as it will be used to implement good maintenance management practices to improve building conditions. Based on the practical implications that highlight the use of existing maintenance management practices to improve the condition of buildings, it is significant that this study developed a maintenance management supportive framework to assist maintenance managers of tertiary institutions surmount the complex task of choosing appropriate maintenance management practices, either outsourcing or in-sourcing, and both to improve the condition of buildings.

Maintenance managers can utilize the framework to help them choose the most successful type of maintenance practice for each type of maintenance management. The study has also provided dominant influential factors to consider when assessing the type of building maintenance practice, either insource or outsource, to give favourable results with funds allocated to maintenance works, in order to overcome the improper choice of maintenance management that has been practiced. The evaluation of quality maintenance management procedures is used to develop indicators for taking supporting action in accordance with defined requirements for tertiary institution ownership.

As a result of factors influencing the choice of maintenance management practices in Nigerian universities, the proposed framework will seek to direct institution building owners (governments) to enforce adequate funding to ensure maintenance works are undertaken based on needs, planned develop maintenance management strategy and condition assessment with effective measures to improve building conditions.

\section{REFERENCES}

Burnard, P. (1991). A Method of Analysing Interview Transcripts in Qualitative Research.

Hassanain, M.A., Froese, T.M. and Vainer, D.D.J. (2001) Development of Maintenance Management Model Based on IAI Standards. Artificial Intelligence in Engineering, 15: 177-93.

Hassanain, Mohammad A., SadiAssaf, Khalaf Al-Ofi, \& Abdullah AlAbdullah. (2013). Factors Affecting Maintenance Cost of Hospital Facilities in Saudi Arabia. Property Management, 31 (4): 297-310.

Hesham, A. (2015). Development of a Maintenance Management Framework to Facilitate the Delivery of Healthcare Provisions in The Kingdom of Saudi Arabia. PhD. Thesis; School of Science and Technology, of Nottingham Trent University Saudi Arabia.

Hesham, A. \& Lai, E. (2015).Recommendation for Improving Maintenance Procedures in a Hospital by Implementing Total Productive Maintenance (TPM).Proceedings of the 2015 International Conference on Industrial Engineering and Operations Management. Dubai, UAE.

Hesham, A., Lai, E. \&McCollin, C. (2014).Development of Framework for Maintenance Management in Healthcare Industry in Saudi Arabia, 20th ISSAT International Conference on Reliability and Quality in Design (RQD 2014).

Hesham, A.,McCollin, C. and Lai, E. (2013). Maintenance Planning in a Saudi Arabian Hospital.Advances in Risk and Reliability Technology Symposium (20th AR2 TS) Loughborough. UK.

Ikediashi, D. I. (2014). A framework for outsourcing facilities management services in Nigeria's public hospitals (Unpublished Doctoral dissertation) Heriot-Watt University.

Julien, H. (2008). The SAGE Encyclopedia of Qualitative Research Methods.SAGE Publishers.

Lee, J. (2003). E-manufacturing: Fundamental, Tools, and Transformation, Robotics and Computer-Integrated Manufacturing, 19 (6), 501-7.

Marks, D. F., and Yardley, L. (2004). Research Methods for Clinical and Health Psychology.

Marquez, C. A. (2007). The Maintenance Management Framework: Models and Methods for Complex Systems Maintenance; London: Springer.

Marquez, C. A. and Gupta, J. N. D. (2006). Contemporary Maintenance Management: Process, Framework and Supporting Pillars. Omega, 34(3), 313-326. doi: 10.1016/j.omega.2004.11.003.

Marquez, C. A., Moreu de León, P., Gómez Fernández, J.F. Parra Márquez, C. and López Campos, M. (2009). The Maintenance Management Framework: A practical View to Maintenance Management, Journal of Quality in Maintenance Engineering, 15 (2),167-178.

Mojela, T. W. (2012). Assessment of the Effectiveness of Public Schools Infrastructure Maintenance System in the Gauteng Province (Unpublished doctoral dissertation). University of Johannesburg, South Africa.

Naughton, M. D., andTiernan, P. (2012).Individualising Maintenance Management: A Proposed Framework and Case Study.Journal of Quality in Maintenance Engineering, 18(3), 267-281. doi:10.1108/13552511211265802.

Prasad Mishra, R., Anand, D. and Kodali, R. (2006), "Development of a Framework for World-Class Maintenance Systems", Journal of Advanced Manufacturing Systems, 5 (2), 141-65.

Takata, S., Kimura, F., Van Houten, F. J. A. M., Westkamper, E., Shopitalni, M., Ceglarek, D. and Lee, J. (2004). Maintenance: Changing Role in Life Cycle Management. CIRP Annals - Manufacturing Technology, $53 \quad$ (2), 643-655; 53(2), 643-655.Retrievedfrom: http://www.sciencedirect.com/science/article/pii/S000785060760033 $\mathrm{X}$.

Tsang, A.H.C., Jardine, A.K.S. and Kolodny, H. (2002). Measuring Maintenance Performance: A Holistic Approach, Journal of Quality in Maintenance Engineering, 19 (7), 691-715.

Waeyenbergh, G. andPintelon, L. (2002). A Framework for Maintenance Concept Development,International Journal of Production Economics, 77 (3), 299-313. 